\title{
Cognitive Emotion Regulation Strategies Used by Critical Care Nurses: A Descriptive-Analytic Study
}

\section{Moghaddam zeabadi S1, Hasandoost F⿻ Kasirlou L $^{3}$, Rashvand $\mathrm{F}^{4}$}

\section{and Hosseinigolafshani SZ4*}

1Emergency Department, School of Paramedicine, Qazvin University of Medical Sciences, Iran

${ }^{2}$ Department of nursing, Tarbiat Modares University, Iran

${ }^{3}$ Student Research Committee, Qazvin University of Medical Sciences, Iran

${ }^{4}$ Department of Critical care Nursing, School of Nursing and Midwifery, Qazvin University of Medical Sciences, Iran

*Corresponding author: Seyedehzahra Hoseinigolafshani, Department of Critical care Nursing, School of Nursing and Midwifery, Qazvin University of Medical Sciences, Iran, Tel: 09168439285; Email: zahragolafshani@yahoo.com

\section{Abstract}

Introduction: Emotions have significant roles in different aspects of life such as coping with stressful and traumatic life events. Therefore, success in life depends not only on intellectual abilities, but also on emotion regulation competence. Emotion regulation is of greater importance in professions with high levels of daily occupational stress such as nursing. The aim of this study was to determine cognitive emotion regulation strategies used by a group of Iranian critical care nurses.

Methods: This descriptive-analytic study was conducted on 193 critical care nurses. They were recruited through stratified random sampling from ICU, CCU, and Hemodialysis center and Emergency departments of six hospitals under supervision of Qazvin university of medical science, qazvin, Iran,. The 36-item Cognitive Emotion Regulation Questionnaire was used for data gathering. Descriptive statistics measures (frequency, mean, and SD) and inferential statistics (T test, Pearson correlation analysis) were used for data description and analysis.

Results: There were significant differences among nurses of different units respecting the mean scores of strategies Acceptance $(\mathrm{P}=0.002)$, Rumination $(\mathrm{P}=0.001)$, Catastrophizing $(\mathrm{P}=0.046)$, and Self-blame $(\mathrm{P}=0.029)$. Age and work experience were correlated with acceptance and putting into perspective strategies while work experience was inversely correlated with rumination strategies. 


\section{Nursing \& Healthcare International Journal}

Conclusion: There are significant differences among the nurses of different critical care units respecting cognitive emotion regulation strategies. Qualitative studies and in-depth interviews are needed to determine factors behind nurses' use of adaptive and maladaptive cognitive emotion regulation strategies.

Keywords: Cognitive emotion regulation; Critical care units; Nursing

\section{Introduction}

Healthcare system has significant roles in protecting and promoting health and hence, it is among the most important components of sustainable development in human societies. In order to effectively perform its healthrelated roles, a healthcare system needs to have healthy, happy, and motivated personnel who are competent enough in providing quality services [1].

As the largest group of healthcare providers [1,2], nurses, particularly critical care nurses, experience high levels of occupational stress. In critical care units, patients' conditions are diverse, unpredictable, and rapidly changing and therefore, nurses need to manage patients' and their families' conditions, concerns, and problems in as short as possible amount of time. Such harsh working condition is a major source of stress for critical care nurses [3-5]. Studies show that compared with nurses in other hospital wards, critical care nurses suffer from higher levels of physical and mental stress $[6,7]$ and therefore, experience greater problems [8].

Working in highly stressful working conditions necessitates remarkable ability to cope with daily emotions. Emotions have critical roles in different aspects of life such as in coping with changes in daily life and also with stressful conditions $[7,8]$. Therefore, success in life depends not only on intellectual abilities, but also on competence in emotion regulation [9]. Effective emotion regulation has various effects on different aspects of life such as interpersonal interactions $[10,11]$, mental health $[10,12]$, and physical health $[10,13]$. Conversely, impaired emotion regulation is among the most significant factors behind the development of health problems and disorders $[9,10,14]$.

Emotion regulation is the individual's cognitive processing in facing traumatic events or stressful conditions. Individuals usually use almost the same emotion regulation patterns; yet, it seems that each individual tends to use some patterns more frequently.
These patterns are called emotion regulation strategies [15].

One of the most common emotion regulation strategies is cognitive emotion regulation [15-17]. Cognitive processes help individuals regulate their emotions and feelings and improve their resistance to extreme emotions and feelings. Cognitive emotion regulation strategies (CERS) are divided into adaptive and maladaptive ones. Adaptive strategies include refocus on planning, positive reappraisal, positive refocusing, putting into perspective, and acceptance, while maladaptive strategies are selfblame, other-blame, rumination, and catastrophizing [14,18-20]. Each strategy is associated with certain outcomes [21]. For example, maladaptive CERSs such as self-blame, other-blame, and catastrophizing are inversely correlated with mental health [22], while adaptive CERSs such as putting into perspective and positive reappraisal have direct correlations with all aspects of quality of life [21-23].

Nurses with unresolved emotional problems experience higher levels of emotional stress [24]. A study showed that nurses experience significantly more emotional problems and have lower emotion regulation abilities than physicians [25]. Another study also reported that emotion regulation, acceptance, and commitment were significant predictors of nurses' job burnout [1].

To the best of our knowledge, there is limited information about the CERSs used by critical care nurses in Iran. Therefore, to narrow this gap, this study sought to determine CERSs used by a group of Iranian critical care nurses.

\section{Materials and Methods}

This was a descriptive-analytic study. Study setting was Emergency Departments, ICU, CCU, and Hemodialysis centerof Bouali, Rajaei, Kowsar, Qods, 22 Bahman, and Velayatteaching hospitals, Qazvin, Iran. All 347 nurses who worked in the critical care units of these six hospitals constituted study population. A random sample of 193 
critical care nurses was recruited through stratified randomly sampling, in which units were considered as strata. Inclusion criteria were a work experience of at least one year in critical care units, no experience of serious stress in the past month, no use of psychiatric medications, and Willingness to participate in the research.

The Cognitive Emotion Regulation Questionnaire (CERQ) was used for data gathering. CERQ was developed by Garnegski et al. for the assessment of CERSs used by individuals after experiencing stressful life events. It contains 36 items on nine CERSs, namely self-blame (items 1, 10, 19, and 28), acceptance (items 2, 11, 20, and 29), rumination (items $3,12,21$, and 30), positive refocusing (items $4,13,22$, and 31 ), refocus on planning (items 5, 14, 23, and 32), positive reappraisal (items 6, 15, 33 , and 24), putting into perspective (items 7, 34, 25, and 16), catastrophizing (items $8,17,35$, and 26), and otherblame (items 9, 18, 27, and 36). The items are scored using a five-point Likert-type scale as follows: 1: "Never"; 2: "Sometimes"; 3: "Regularly"; 4: "Often"; and 5: "Always". The score of each strategy is calculated through summing the scores of its items and can range from 4 to 20. Therefore, the total CERQ score ranges from 36 to 180 $[16,18,20]$. Garnefski, et al. reported that the Cronbach's alpha of the questionnaire was 0.93 [18]. Hasani, et al. also assessed the psychometric properties of the Persian CERQ and reported that its items can be loaded on nine factors with eigen values of $0.53-0.86$ which explained $74 \%$ of the total variance of the strategies [19].

The aim and the process of the study were explained to participants and their informed consents were secured. They were ensured that their personal information would be dealt with confidentially, they could withdraw from the study voluntarily, and they would have access to study results.

Collected data were coded and entered into the SPSS, v 24. Descriptive statistics (such as frequency, mean, and standard deviation) were used for data description, while inferential statistics methods (T test, ANOVA, and Pearson correlation analysis) were used for data analysis.

\section{Results}

As shown in Table 1, 87\% of nurses were male, $65.3 \%$ were married, 93.8\% held bachelor's degree, and 33.2\% were employed under contract or under the national rule of post-graduation mandatory service. The means age and work experience were respectively $29.9 \pm 5.65$ and $6.79 \pm 5.4$.

\begin{tabular}{|c|c|c|}
\hline \multirow{2}{*}{ Gender } & Characteristics & N (\%) \\
\cline { 2 - 3 } & Female & $168(87)$ \\
\hline \multirow{2}{*}{$\begin{array}{c}\text { Educational } \\
\text { status }\end{array}$} & Male & $25(13)$ \\
\hline \multirow{2}{*}{ Marital status } & Bachelor's degree & $181(93.8)$ \\
\cline { 2 - 3 } & Master's degree & $12(6.2)$ \\
\hline \multirow{3}{*}{$\begin{array}{c}\text { Employment } \\
\text { status }\end{array}$} & Married & $126(65.3)$ \\
\cline { 2 - 3 } & Single & $67(34.7)$ \\
\cline { 2 - 3 } & Post-graduation service & $64(33.2)$ \\
\hline \multicolumn{2}{|c|}{ Under contract } & $64(33.2)$ \\
\hline \multicolumn{2}{|c|}{ Conditional official } & $61(2.1)$ \\
\hline \multicolumn{2}{|c|}{ Work experience (Years) } & $\mathbf{2 9 . 9 \pm 5 . 6 5}$ \\
\hline
\end{tabular}

Table 1: Participants' demographic characteristics

(Table 2) presents the mean scores of CERSs based on working units. Statistical analyses showed there was significant differences among nurses of different working units respecting the mean of strategies acceptance $(\mathrm{P}=$
0.002), rumination $(\mathrm{P}=0.001)$, catastrophizing $(\mathrm{P}=$ 0.046), and self-blame $(\mathrm{P}=0.029)$. The lowest and the highest scores of acceptance strategies belonged respectively to Emergency department and CCU nurses. 


\section{Nursing \& Healthcare International Journal}

Nurses of Emergency Department and CCU respectively obtained the highest and lowest scores for rumination strategies. The lowest and the highest scoreof Catastrophizing strategies, were respectively obtained by
CCU and Hemodialysis nurses. Finally, the lowest and the highest self-blame strategies belonged respectively to CCU and Hemodialysis nurses.

\begin{tabular}{|c|c|c|c|c|c|c|}
\hline \multirow{2}{*}{ Strategies } & ICU & CCU & Dialysis unit & ED & \multirow{2}{*}{ F } & \multirow{2}{*}{ P value } \\
\cline { 2 - 5 } & Mean \pm SD & Mean \pm SD & Mean \pm SD & Mean \pm SD & & \\
\hline Acceptance & $12.52(2.68)$ & $15.6(1.95)$ & $12.37(2.19)$ & $12.04(2.82)$ & 4.44 & 0.002 \\
\hline Rumination & $12.3(2.14)$ & $9.6(2.95)$ & $12.5(1.92)$ & $13.4(2.97)$ & 4.62 & 0.001 \\
\hline Positive refocusing & $13.64(2.1)$ & $14.6(3.3)$ & $12.75(2.37)$ & $12.76(3.11)$ & 1.23 & 0.299 \\
\hline Refocus on planning & $13.8(2.76)$ & $13.6(4.74)$ & $14.37(3.24)$ & $15.64(2.87)$ & 1.78 & 0.134 \\
\hline Catastrophizing & $9.9(2.04)$ & $8.6(3.13)$ & $10.87(1.95)$ & $10.36(3.02)$ & 2.46 & 0.046 \\
\hline Positive reappraisal & $13.73(2.99)$ & $14.3(5.1)$ & $14.37(3.42)$ & $15.12(2.72)$ & 0.898 & 0.466 \\
\hline Putting into perspective & $13(2.53)$ & $13.7(3.26)$ & $12.87(2.94)$ & $13.32(2.34)$ & 0.915 & 0.457 \\
\hline Other-blame & $10.42(2.44)$ & $12.2(3.45)$ & $9(2.5)$ & $10.32(2.6)$ & 1.79 & 0.132 \\
\hline Self-blame & $10.76(2.43)$ & $10(3.46)$ & $11.62(2.38)$ & $11.48(2.8)$ & 2.752 & 0.029 \\
\hline Total & $110.52(14.07)$ & $112.9(14.3)$ & $111(12.63)$ & $115.16(11.52)$ & 1.44 & 0.221 \\
\hline
\end{tabular}

Table 2: The mean scores of CERSs based on nurses' working units (the results of the one-way analysis of variance)

The correlations of CERSs with demographic characteristics are shown in Table 3. Rumination strategies had an inverse correlation with work experience. Nurses with greater work experience used this strategies less frequently $(\mathrm{r}=-0.189 ; \mathrm{P}<$ 0.01).Moreover, putting into perspective strategies was directly correlated with age so that its use increased with age $(\mathrm{r}=0.144 ; \mathrm{P}<0.05)$. Furthermore, acceptance strategies was directly correlated with both age $(\mathrm{r}=$ 0.212; $\mathrm{P}<0.01)$ and work experience $(\mathrm{r}=0.214 ; \mathrm{P}<0.01)$. In other words, nurses with older ages and greater work experience used this strategy more frequently. CERSs had no significant correlations with gender and employment, marital, and educational status ( $\mathrm{P}>0.05)$.

\begin{tabular}{|c|c|c|c|c|c|c|c|c|c|c|c|c|}
\hline Strategies & 1 & 2 & 3 & 4 & 5 & 6 & 7 & 8 & 9 & 10 & 11 & 12 \\
\hline 1. Age & & & & & & & & & & & & \\
\hline $\begin{array}{c}\text { 2. Work } \\
\text { experience }\end{array}$ & $0.943^{* *}$ & & & & & & & & & & & \\
\hline 3. Self-blame & -0.015 & $0.066-$ & & & & & & & & & & \\
\hline 4. Acceptance & $0.212^{* *}$ & $0.214^{* *}$ & $0.217^{* *}$ & & & & & & & & & \\
\hline 5. Rumination & $0.13-$ & $-0.189 * *$ & $0.531^{* *}$ & 0.007 & & & & & & & & \\
\hline $\begin{array}{l}\text { 6. Positive } \\
\text { refocusing }\end{array}$ & 0.112 & 0.133 & _0.035 & $0.407^{* *}$ & _0.207** & & & & & & & \\
\hline $\begin{array}{l}\text { 7. Refocus on } \\
\text { planning }\end{array}$ & 0.039 & 0.003 & $0.265^{* *}$ & 0.094 & $0.31^{* *}$ & $0.497^{* *}$ & & & & & & \\
\hline $\begin{array}{l}\text { 8. Positive } \\
\text { reappraisal }\end{array}$ & 0.081 & 0.045 & 0.215 & 0.068 & $0.191^{* *}$ & $0.525^{* *}$ & $0.739 * *$ & & & & & \\
\hline $\begin{array}{l}\text { 9. Putting into } \\
\text { perspective }\end{array}$ & $0.144^{*}$ & 0.116 & $0.259^{* *}$ & $0.373^{* *}$ & 0.081 & $0.529^{* *}$ & $0.454^{* *}$ & $0.536^{* *}$ & & & & \\
\hline $\begin{array}{c}10 . \\
\text { Catastrophizing }\end{array}$ & -0.053 & -0.118 & $0.436^{* *}$ & 0.027 & $0.48^{* *}$ & -0.278 & 0.017 & -0.015 & -0.028 & & & \\
\hline 11. Other-blame & -0.001 & 0 & $0.228^{* *}$ & $0.273^{* *}$ & 0.086 & -0.071 & -0.106 & -0.117 & 0.063 & $0.352^{* *}$ & & \\
\hline $\begin{array}{l}\text { 12. Total strategy } \\
\text { score }\end{array}$ & 0.077 & 0.023 & $0.649^{* *}$ & $0.484^{* *}$ & $0.526^{* *}$ & $0.464^{* *}$ & $0.686^{* *}$ & $0.656^{* *}$ & $0.662^{* *}$ & $0.399 * *$ & $0.339 * *$ & \\
\hline
\end{tabular}

Table 3: The correlation of CERSs with nurses' demographic characteristics (the results of Pearson correlation analysis) 


\section{Nursing \& Healthcare International Journal}

\section{Discussion}

Study findings revealed that coronary care nurses obtained the lowest scores for the three maladaptive CERSs of rumination, catastrophizing, and self-blame and the highest score for the adaptive strategies of acceptance. In other words, coronary care nurses used Adaptive strategies more and Maladaptive strategies. Similarly, a study showed that most nurses used refocus on planning, positive reappraisal, and putting into perspective strategies more frequently than self-blame, other-blame, and catastrophizing strategies [1]. On the contrary, a study showed that the highest-scored strategies used by nurses was the maladaptive strategy of rumination [26]. Another study also showed that compared with physicians, nurses suffered from more emotional problems, had less control over their emotions, and had limited interpersonal interactions [27]. These contradictory results may be due to the fact that nurses in our study were from critical care units, while nurses in those studies had been recruited from different hospital wards.

Findings also indicated that coronary care nurses obtained the highest score for the adaptive strategy of acceptance. According to Eesazadeh, acceptance strategies has the greatest power in predicting nurses' quality of life [26]. Therefore, coronary care nurses may have better mental health status and greater quality of life compared with other nurses. Conversely, Hemodialysis nurses in our study obtained the highest scores for the maladaptive strategies include Catastrophizing and Selfblame. Royani, et al. and Kersten, et al. also reported that compared with nurses in other hospital wards and units, Hemodialysis nurses suffered from higher levels of occupational stress $[27,28]$. The maladaptive strategy of catastrophizing is directly correlated with occupational stress so much that nurses with higher levels of occupational stress used this strategies more frequently [29]. Moreover, Catastrophizing and Self-blame maladaptive strategies were reported to have direct correlations with job burnout [1]. Generally, staff who avoid emotion expression for long periods of time, such as Hemodialysis nurses [30], are more at risk for experiencing job burnout and using maladaptive strategies [31]. Given the significant effects of job burnout on the quality of nursing care, further studies are needed to reduce nurses' job burnout through facilitating their use of adaptive stategies. According to Gonnelli, et al. and Montero-Marín, et al., mastery over the concept of cognitive emotion regulation provides nurses with better opportunities for discovering their abilities in coping with stressful conditions [30,31]. We also found that Emergency department nurses obtained the lowest score of acceptance adaptive strategies and the highest score for the rumination maladaptive strategies. Eesazadeh also found that Emergency department nurses obtained high rumination scores [26]. Moreover, Barghandan and Khalatbari found rumination and catastrophizing as the most commonly used strategies among emergency department nurses. They also noted that these strategies were inversely correlated with quality of life [32]. Accordingly, more studies are needed to determine factors behind the wide use of maladaptive strategies by nurses in Emergency departments and Hemodialysis units. Our findings also showed the inverse correlation of rumination strategies with work experience. In other words, more experienced nurses less frequently used the rumination strategies. This is in line with the findings of an earlier study which showed that nurses with limited work experience suffered from higher levels of occupational stress [33]. Another finding of the present study was the direct significant correlation of acceptance strategies with work experience so that nurses with higher work experience more frequently used this strategy. Other strategies were not significantly correlated with work experience.

Study findings also indicated that age was directly correlated with putting into perspective and acceptance strategies. In other words, older nurses more frequently used these strategies than their younger counterparts. Similarly, two earlier studies reported the inverse correlation of age with occupational stress, denoting that younger people are more at risk for experiencing occupational stress [34,35]. These findings can be attributed to the fact that nurses gradually become more experienced in coping with stressors and also in task performance and hence, experience lower levels of stress. However, three studies showed that age was not significantly correlated with occupational stress and mental health $[27,36,37]$.

\section{Conclusion}

Study findings suggest significant differences among the nurses of different critical care units respecting CERSs in thatCCU nurses mainly use adaptive CERSs, while Emergency department and Hemodialysis nurses mainly use maladaptive CERSs. Qualitative studies and in-depth interviews are needed to determine factors behind nurses' use of adaptive and maladaptive CERSs.

\section{Acknowledgement}

This study came from a master's thesis in critical care nursing which has the approval of the Ethics Committee of 


\section{Nursing \& Healthcare International Journal}

Qazvin University of Medical Sciences, Qazvin, Iran (with the approval code of IR.QUMS.REC1395.259). Hereby, we would like to thank the authorities of the university and the nurses who participated in this study.

\section{References}

1. Kabir MJ, Heidari A, Etemad K, Gashti AB, Jafari N, et al. (2016) Job Burnout, Job Satisfaction, and Related Factors among Health Care Workers in Golestan Province, Iran. Electronic physician 8(9): 2924-2930.

2. Moghaddasi J, Mehralian H, Aslani Y, Masoodi R, Amiri M (2013) Burnout among nurses working in medical and educational centers in Shahrekord, Iran. Iran J Nurs Midwifery Res 18(4): 294-297.

3. Lai HL, Lin YP, Chang HK, Wang SC, Liu YL, et al. (2008) Intensive care unit staff nurses: predicting factors for career decisions. Journal of clinical nursing 17(14): 1886-1896.

4. Sarafis P, Rousaki E, Tsounis A, Malliarou M, Lahana L, et al. (2016) The impact of occupational stress on nurses' caring behaviors and their health related quality of life. BMC nursing 15: 56.

5. Kane P (2009) Stress causing psychosomatic illness among nurses. Indian J Occup Environ Med 13(1): 2832.

6. Sharma P, Davey A, Davey S, Shukla A, Shrivastava K, et al. (2014) Occupational stress among staff nurses: Controlling the risk to health. Indian J Occup Environ Med 18(2): 52-56.

7. Saedpanah D, Salehi S, Moghaddam LF (2016) The Effect of Emotion Regulation Training on Occupational Stress of Critical Care Nurses. J Clin Diagn Res 10(12): VC01-VC04.

8. Najimi A, Goudarzi AM, Sharifirad G (2012) Causes of job stress in nurses: A cross-sectional study. Iran J Nurs Midwifery Res 17(4): 301-305.

9. Honari A, Shamoli L (2017) The Effectiveness of Cognitive Behavioural Couple Therapy on Marital Stress and Emotional Skills of Infidel Couples in Shiraz. International Journal of Medical Research \& Health Sciences 6(2): 83-90.

10. Koole SL, Webb TL, Sheeran PL (2015) Implicit emotion regulation: feeling better without knowing why. Current Opinion in Psychology 3: 6-10.
11. Hafner M, Ijzerman $H$ (2011) The face of love: spontaneous accommodation as social emotion regulation. Pers Soc Psychol Bull 37(12): 1551-1563.

12. Aldao A, Nolen Hoeksema S, Schweizer S (2010) Emotion-regulation strategies across psychopathology: A meta-analytic review. Clin Psychol Rev 30(2): 217-237.

13. Chen E, Miller G (2014) Early life environments, emotion regulation, and the biological mechanisms of disease. In Gross JJ (Ed) Handbook of emotion regulation 586-595.

14. Azarian A, Farokhzadian AA, Motaghi Z (2016) A study of the relationship between cognitive regulation of emotions and aggression in the female students of the first grade of high school in Rezvanshahr. International Journal of Humanities and Cultural Studies: 320-325.

15. Kring AM, Sloan DM (2009) Emotion regulation and psychopathology: A transdiagnostic approach to etiology and treatment: Guilford Press.

16. Shakeri M, Parhoon H, parhoonc A, Parhoon K (2017) Investigating the role of cognitive emotion regulation strategies in prediction of test anxiety in Students. Research Communications in Psychology, Psychiatry and Behavior 101-106.

17. Moyal N, Henik A, Anholt G (2014) Cognitive strategies to regulate emotions - current evidence and future directions. Front Psychol 4: 1019.

18. Garnefski N, Rieffe C, Jellesma F, Terwogt MM, Kraaij V (2007) Cognitive emotion regulation strategies and emotional problems in 9 - 11-year-old children: the development of an instrument. Eur Child Adolesc Psychiatry 16(1): 1-9.

19. Hasani J (2011) Psychometric properties of emotional cognitive regulation questionnaire. Journal of Clinical Psychology 3(3): 84-73.

20. Zhu X, Auerbach RP, Yao S, Abela JRZ, Xiao J, Tong X (2008) Psychometric properties of the Cognitive Emotion Regulation Questionnaire: Chinese version. Cognition and Emotion 22(2): 288-307.

21. Fairholme C, Boisseau C, Ellard K, Ehrenreich T, David BH, et al. (2010) Emotions, Emotion Regulation, And Psychological Treatment: A Unified Perspective 283309. 


\section{Nursing \& Healthcare International Journal}

22. Amone P, Olak K, Boitumelo V, Mberengwa DS (2017) Cognitive emotion regulation strategies and mental health problems in war-affected youth in Northern Uganda: findings from the WAYS study. J Ment Health 11: 1-7.

23. Manju HK, Basavarajappa (2016) Role of Emotion Regulation in Quality of Life. The International Journal of Indian Psychology 4(1): 81.

24. Cecil P, Glass N (2015) An exploration of emotional protection and regulation in nurse-patient interactions: The role of the professional face and the emotional mirror. Collegian 22(4): 377-385.

25. Kovacs M, Kovacs E, Hegedu K (2010) Emotion work and burnout: cross-sectional study of nurses and physicians in Hungary. Croat Med J 51(5): 432-442.

26. Easazadeh A (2016) The Predictive Role of Cognitive Emotion Regulation Strategies in Marital Satisfaction and Job Burnout among Nurses. Iranian Journal of Nursing 29(102): 22-31.

27. Royani Z, Sabzi Z, Mancheri H (2016) The Relationship Between Job Stressors and Coping Strategies From Critical Nurses. Iranian Journal of Psychiatric Nursing 4(3): 25-32.

28. Kersten M, Kozak A, Wendeler D, Paderow L, Nubling M, et al. (2014) Psychological stress and strain on employees in dialysis facilities: a cross-sectional study with the Copenhagen Psychosocial Questionnaire. J Occup Med Toxicol 9(1): 4.

29. Mikaeili N, Ghaffari M (2016) Role of Thought Action Fusion and Cognitive Emotion Regulation Strategies in Predicting The Job Stress of Psychiatric and Neurology Wards Nurses. Iranian journal of nursing research. September-october 11(4): 1-10.

30. Gonnelli C, Raffagnino R, Puddu L (2016) The Emotional Regulation in Nursing Work: An
Integrative Literature Review and Some Proposals for its Implementation in Educational Programs. Journal of Nursing and Health Science (IOSR-JNHS) 5(6): 4349.

31. Montero Marin J, Garcia Campayo J, Mosquera Mera D, Lopez del Hoyo Y (2009) A new definition of burnout syndrome based on Farber's proposal. J Occup Med Toxicol 4: 31.

32. Barghandan S, Khalatbari J (2017) The Correlation between Cognitive Emotion Regulation and Spiritual Intelligence with Quality of Life among Emergency Department Nurses. Iran Journal of Nursing 21(104): 46-54.

33. Motamed-Jahromi M, Fereidouni Z, Dehghan A (2017) Effectiveness of Positive Thinking Training Program on Nurses' Quality of Work Life through Smartphone Applications. Int Sch Res Notices 2017: 4965816.

34. Mosadeghrad AM (2013) Occupational stress and turnover intention: implications for nursing management. International journal of health policy and management 1(2): 169-176.

35. Tajvar A, Saraji GN, Ghanbarnejad A, Omidi L, Hosseini SS, et al. (2015) Occupational stress and mental health among nurses in a medical intensive care unit of a general hospital in Bandar Abbas in 2013. Electronic physician 7(3): 1108-1113.

36. Mollart L, Skinner VM, Newing C, Foureur M (2013) Factors that may influence midwives work-related stress and burnout. Women Birth 26(1): 26-32.

37. Juthberg C, Eriksson S, Norberg A, Sundin K (2010) Perceptions of conscience, stress of conscience and burnout among nursing staff in residential elder care. J Adv Nurs 66(8): 1708-1718. 